Composites Science and Technology 40 (1991) 31-46

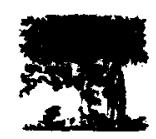

\title{
Comparison of Bevel and Tulip Triggered Pultruded Tubes for Energy Absorption
}

\author{
Michael J. Czaplicki, Richard E. Robertson* \\ Department of Materials Science and Engineering, University of Michigan, \\ Ann Arbor, Michigan 48109-2136, USA \\ $\&$
}

\section{Peter H. Thornton}

Department of Materials Science, Ford Motor Company,

Dearborn, Michigan 48121-2053, USA

(Received 25 September 1989; revised version received 9 January 1990; accepted 28 February 1990)

\begin{abstract}
The crushing behavior of E-glass/polyester and E-glass/vinyl ester pultruded tubes has been found to be significantly different for tulip triggered specimens as compared with bevel triggered specimens. Up to $100 \%$ more energy per unit weight was absorbed by tulip triggered tubes. In addition, the crushing was more controlled and predictable with the tulip trigger. The morphology of the material in the crushing zone differed in the amount and the pattern of fracture. The fracture pattern and crushing behavior initiated by both triggers were found not to change during crushing. The difference in crushing appeared to arise from the different abilities of the tubes to support load because of the different geometry of individual load-carrying structures that resulted from triggering.
\end{abstract}

\section{INTRODUCTION}

Polymer composite structures have been found to be good absorbers of energy when crushed and the crushing is progressive. ${ }^{1-3}$ The crush behavior

* To whom correspondence should be addressed.

Composites Science and Technology 0266-3538/90/\$03.50 (C) 1990 Elsevier Science Publishers Ltd, England. Printed in Great Britain 


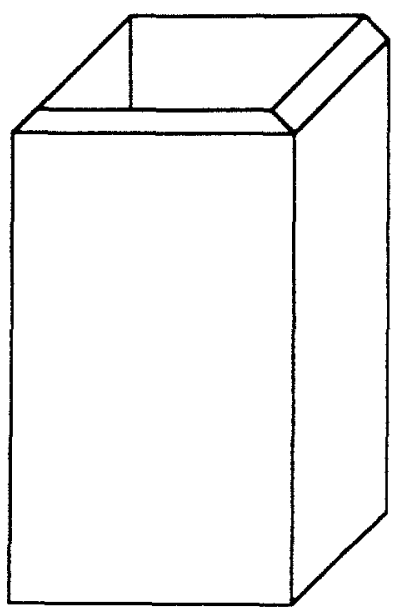

(a)

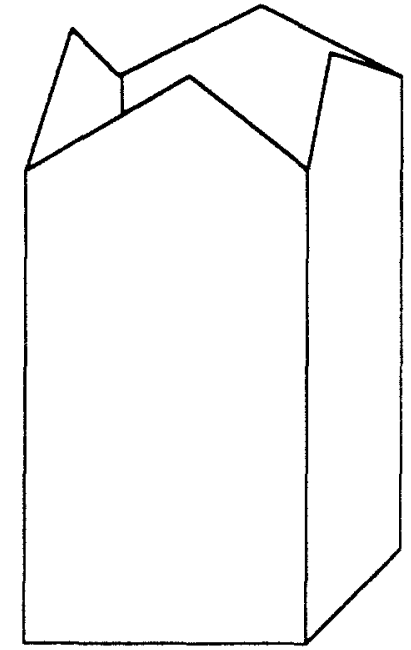

(b)

Fig. 1. (a) Bevel triggered tube, (b) tulip triggered tube.

of a number of composites has been investigated, ${ }^{4.5}$ but a fundamental understanding of the crushing process does not exist. Among the variables known to affect energy absorption in composite structures is the method of failure initiation, which is commonly called triggering. ${ }^{6}$ The crushing of a structure is generally triggered by providing a zone of stress concentration which initiates crush and away from which the crush propagates. The bevel trigger (Fig. 1(a)), produced by beveling the end edges of a tube to sharp edges along the inside surface, is the initiator that is most frequently used in energy absorption studies. ${ }^{7.8}$ Thornton has found that a trigger of different geometry, called the tulip trigger, affords an improvement in energy absorption and crush stability as compared with the bevel trigger. ${ }^{9}$ The geometry of the tulip trigger is such that each of the four tube walls come to a point at the center of the wall and then slope downward to the lowest point at the tube corners, as shown in Fig. 1(b). The reason for the difference in crushing behavior of identical tubes with bevel and tulip triggers, however, has not been fully understood. Work is reported here of an examination of differences in the crushing process in otherwise identical tubes arising from the bevel and tulip triggers.

\section{EXPERIMENTAL}

E-Glass/polyester and E-glass/vinyl ester pultruded tubes were tested using both bevel and tulip triggers. The tubes had a nominal glass content of $52 \%$ by weight. The glass reinforcement consisted of continuous uniaxial fiber 


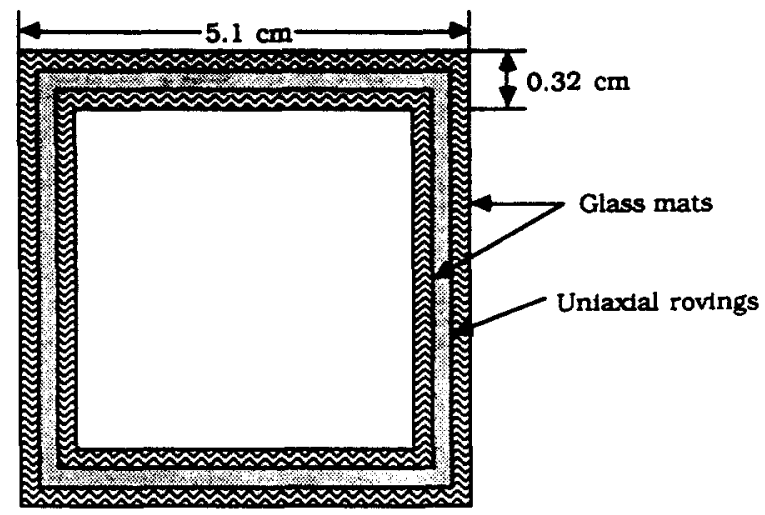

Fig. 2. Schematic diagram of tube layup.

bundles parallel with the tube axis in the tube center and continuous random fibers on each of the tube surfaces, as shown in Fig. 2. About $60 \%$ of the total glass content was from the uniaxial rovings and $40 \%$ from the random fibers. These pultrusions are made by pulling continuous glass fibers through a resin bath around a mandrel and then through a heated die to produce tubes of constant cross-section. The tubes are cut to various lengths after cooling. During pultrusion, the tube surfaces may be wrapped with glass fabrics to produce a product with improved lateral support, and this was done for the specimens used in this study.

Specimens were crushed with a $20000 \mathrm{lb}(100 \mathrm{kN})$ load capacity Instron machine at a speed of $2.5 \mathrm{~cm} / \mathrm{min}$. All specimens were 6 in $(15 \mathrm{~cm})$ in length and were crushed for about 4 in $(10 \mathrm{~cm})$. Crushing was initiated in all tubes by either a bevel or tulip trigger. A load-displacement curve was recorded for each test, and from this curve, a mean load and specific energy absorption, the energy absorption per unit weight, were calculated. Following crushing, specimens were mounted and polished for macroscopic and microscopic evaluation.

\section{RESULTS}

Mean load values for the crush tests are given in Table 1 . The mean load values recorded are seen to be significantly higher for the tulip triggered specimens than for bevel triggered specimens for both polyester and vinyl ester tubes. This is consistent with data from previous work where bevel and tulip triggered specimens were compared. ${ }^{6,9}$ There were clear observable differences during crushing in the general behavior of tubes with the two types of triggers. The delamination cracks between the uniaxial fibers and the glass mats were shorter for tulip triggered tubes. This difference in 
TABLE 1

Mean Crush Load Data for Crushed Specimens

\begin{tabular}{lcccc}
\hline Specimen type & $\begin{array}{c}\text { Mean } \\
\text { load } \\
(k N)\end{array}$ & $\begin{array}{c}\text { Sample } \\
\text { size }\end{array}$ & $\begin{array}{c}S D \\
(k N)\end{array}$ & $\begin{array}{c}90 \% \\
\text { confidence } \\
(k N)\end{array}$ \\
\hline Polyester bevel & $21 \cdot 3$ & 5 & $1 \cdot 1$ & $20 \cdot 3-22 \cdot 4$ \\
Polyester tulip & $29 \cdot 4$ & 5 & $1 \cdot 1$ & $28 \cdot 4-30 \cdot 5$ \\
Vinyl ester bevel & 28.0 & 4 & $3 \cdot 5$ & $23 \cdot 4-32 \cdot 6$ \\
Vinyl ester tulip & $55 \cdot 8$ & 5 & $4 \cdot 5$ & $52 \cdot 7-59 \cdot 4$ \\
\hline
\end{tabular}

triggering was most apparent for vinyl ester specimens but could still be clearly discerned for polyester specimens. Another difference was the degree of fracturing that occurred for specimens with each type of trigger. The glass mats on the inside and outside surfaces fractured at regularly spaced intervals for tubes of both resin and trigger types. These fracture lines, however, were more closely spaced for tulip than for bevel triggered specimens. This accounted for the greater degree of fracture exhibited in tulip triggered specimens. A schematic illustration of the fracture lines is shown in Fig. 3. Nearly all of the fracture that takes place in the surface glass mats occurs at the fracture lines. Therefore, more closely spaced fracture lines result in more total fracture of the tube. Figure 4 shows a longitudinal cross-section of vinyl ester specimens that were crushed with tulip and bevel triggers respectively. Figure 5 shows cross-sections for tulip and bevel triggered polyester specimens. These photographs contrast the fracture line separation and the amount of fracture for both tube types.

From observation of the crushing process, the depth of delamination between the glass mats and uniaxial fibers was seen to be related to the distance between fracture lines. For tubes where delamination does not penetrate deeply, the fracture lines remain closely spaced. Conversely, deep delamination leads to an increased distance between fracture lines. Table 2 lists the distance between fracture lines for different specimen types. Comparison with the data listed in Table 1 shows a correlation between mean load and fracture line distance.

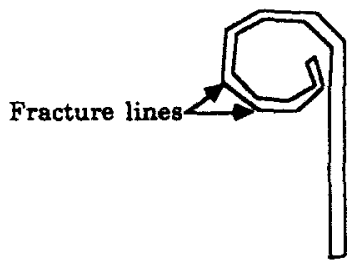

Side View

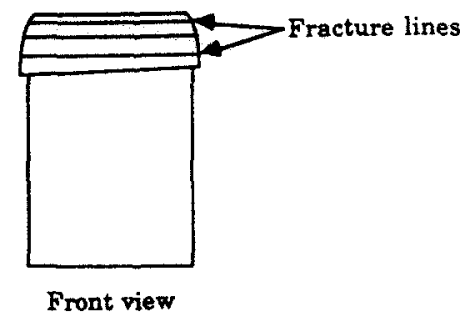

Fig. 3. Schematic illustration of fracture lines. 


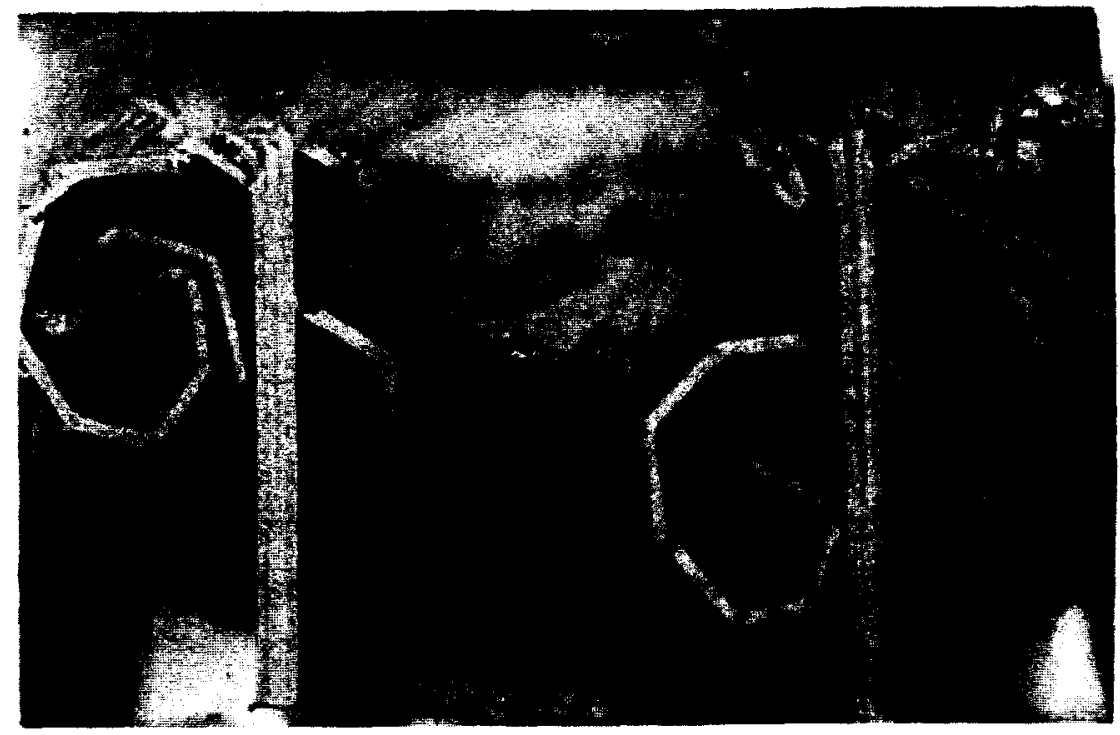

(a)

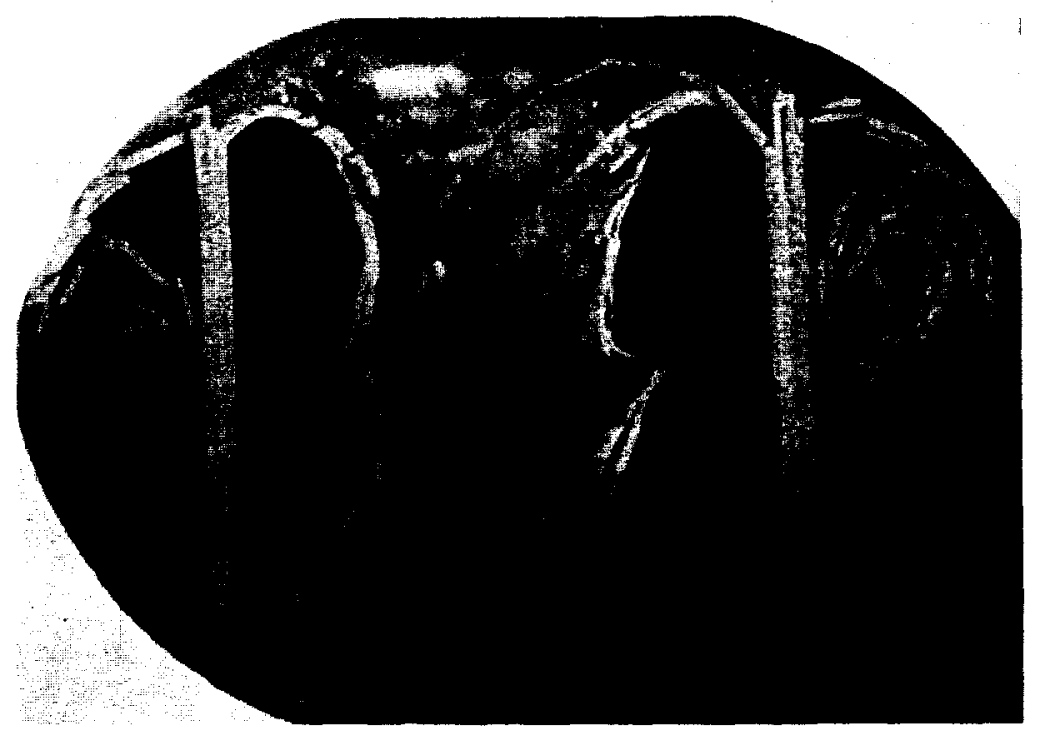

(b)

Fig. 4. Longitudinal cross-section of vinyl ester tubes: (a) bevel trigger; (b) tulip trigger.

Wall delamination occurs when crushing is first initiated. The delamination penetrates and then stops as a fracture line is created. After formation of the first fracture line, delamination restarts, and penetrates some characteristic distance along the uniaxial fiber/glass mat interface, after which another fracture line is created. This process of delamination and fracture line formation occurs for the entire distance that the tube is crushed. 


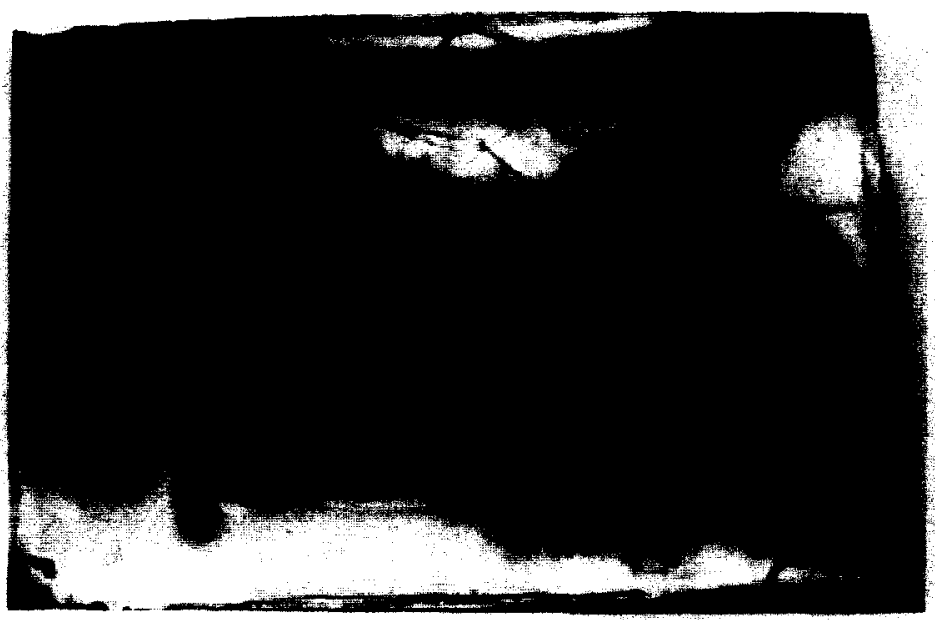

(a)

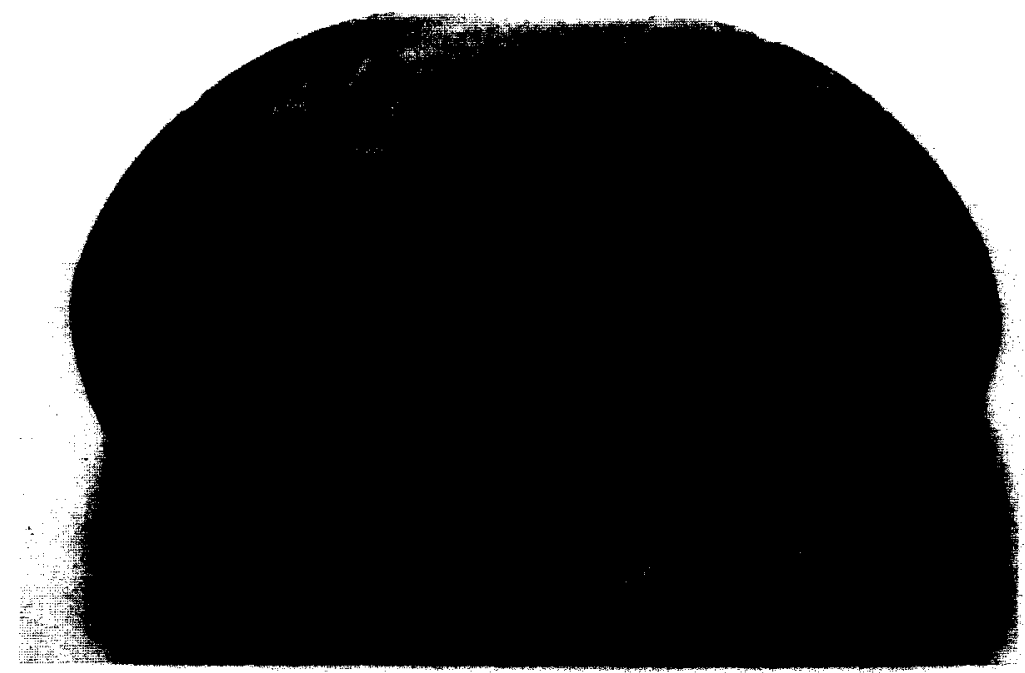

(b)

Fig. 5. Longitudinal cross-section of polyester tubes: (a) bevel trigger; (b) tulip trigger.

Both the depth of delamination and the distance between fracture lines are fairly regular for a specific tube and trigger. The regularity of the fracture line distance is indicated by the standard deviations in Table 2 .

The delamination of the tube does not always occur precisely at the interface of the glass mats and uniaxial fibers. Generally, some of the uniaxial fibers do adhere to the glass mats and become part of the fracture lines. However, these represent a small fraction of the uniaxial fibers. For polyester tubes, most uniaxial fibers are flattened and directed to either the inside or outside of the tube during crushing, but when the load is removed 
TABLE 2

Fracture Line Distance Data

\begin{tabular}{lcccc}
\hline Specimen type & $\begin{array}{c}\text { Fracture } \\
\text { distance } \\
(\mathrm{mm})\end{array}$ & $\begin{array}{c}\text { Sample } \\
\text { size }\end{array}$ & $\begin{array}{c}\text { SD } \\
(\mathrm{mm})\end{array}$ & $\begin{array}{c}90 \% \\
\text { confidence } \\
(\mathrm{mm})\end{array}$ \\
\hline Polyester bevel & 7.2 & 25 & 0.6 & $6 \cdot 3-8.2$ \\
Polyester tulip & $5 \cdot 2$ & 35 & 0.4 & $4 \cdot 6-5 \cdot 9$ \\
Vinyl ester bevel & 8.5 & 20 & $0 \cdot 7$ & $7 \cdot 3-9 \cdot 7$ \\
Vinyl ester tulip & $4 \cdot 1$ & 42 & 0.2 & $3 \cdot 7-4 \cdot 4$ \\
\hline
\end{tabular}

the fibers relax and are directed upward. Some fibers, again a minority, fracture at lengths approximately the same as the distance between fracture lines and become part of the powdered resin debris produced during crushing. Conversely, nearly all of the uniaxial fibers in vinyl ester tubes break and become the major part of the crushing debris generated. The splaying behavior of the unidirectional fibers seen during the crushing of polyester tubes does not occur with vinyl ester tubes.

The depth of delamination, although corresponding to the distance between fracture lines, also appears to affect the crushing stability. The crushing stability is manifested by the constancy of the load during the crushing test. Figures 6-9 show typical load-displacement curves for each type of specimen tested. The load values recorded in these graphs are seen to be more constant and vary less for tulip triggered (Figs 7 and 9) than for bevel triggered (Figs 6 and 8) specimens. Not only are the load values much higher, but the load is more constant and load fluctuations are smaller. Load constancy is an important characteristic for determining a good energy

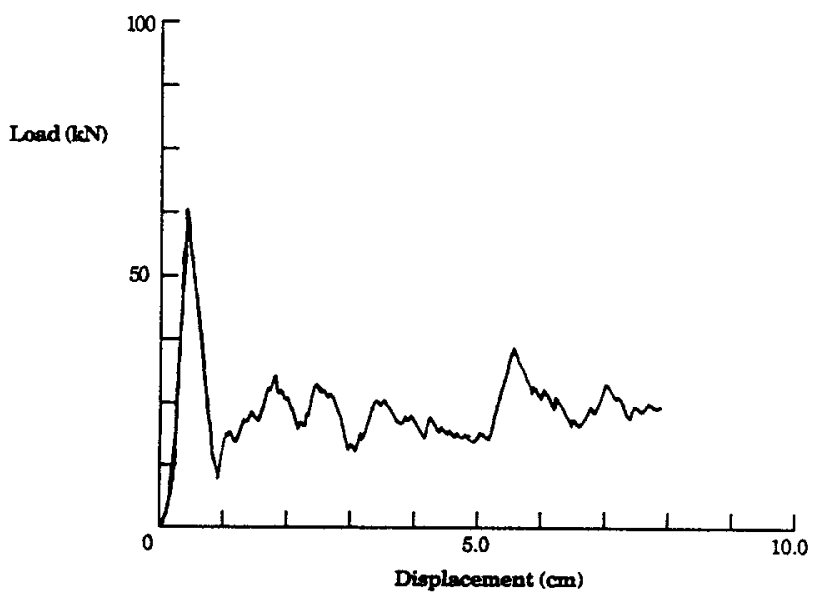

Fig. 6. Load-displacement curve for vinyl ester bevel triggered tube. 


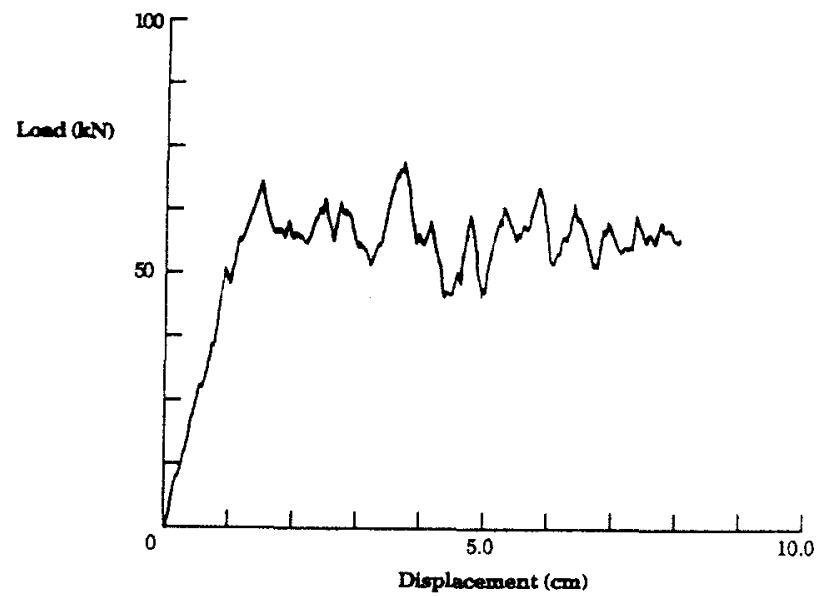

Fig. 7. Load-displacement curve for vinyl ester tulip triggered tube.

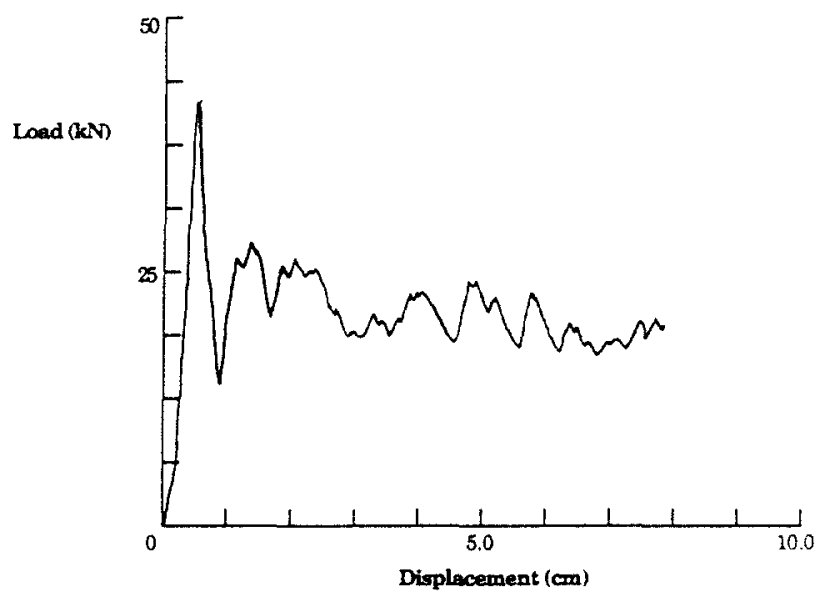

Fig. 8. Load-displacement curve for polyester bevel triggered tube.

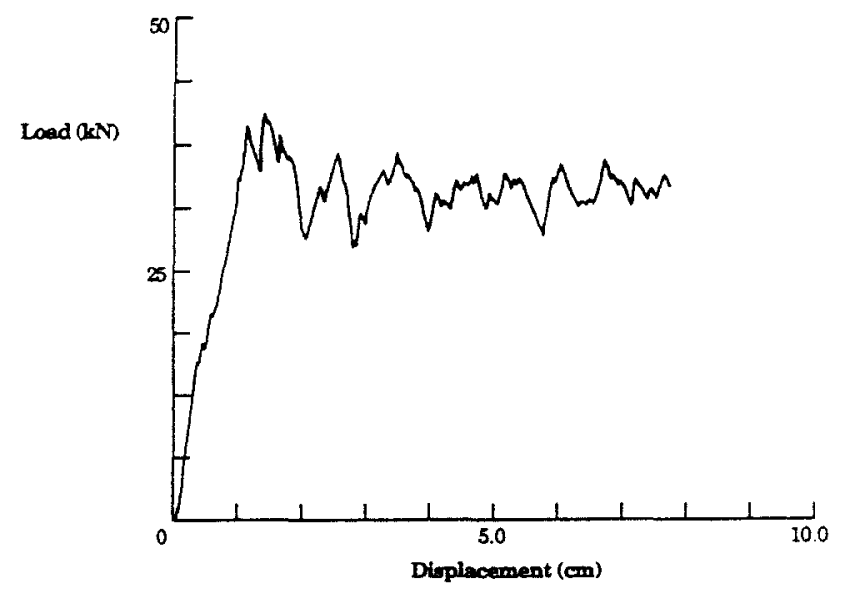

Fig. 9. Load-displacement curve for polyester tulip triggered tube. 


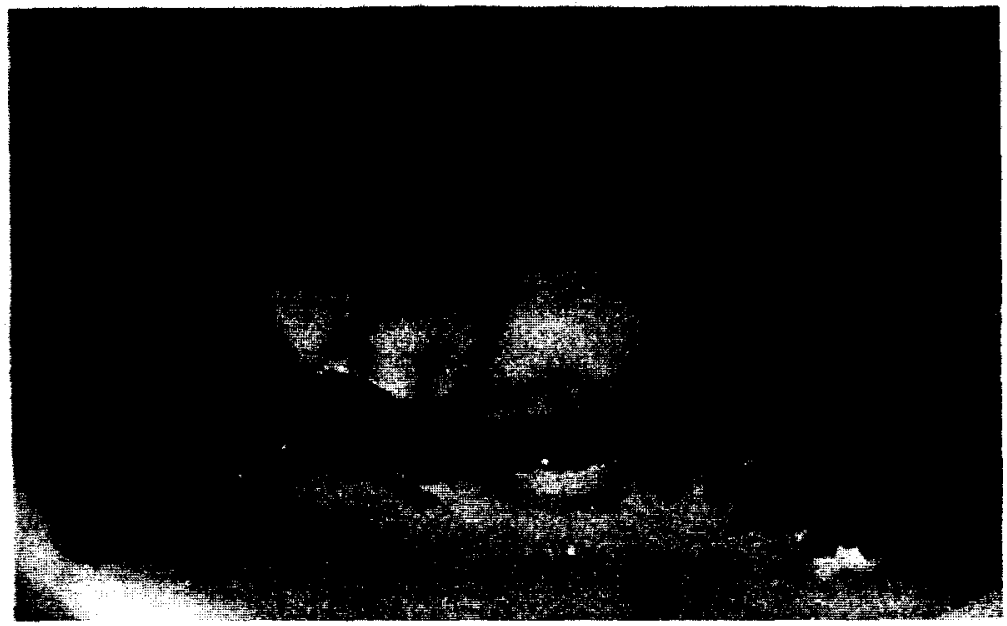

(a)

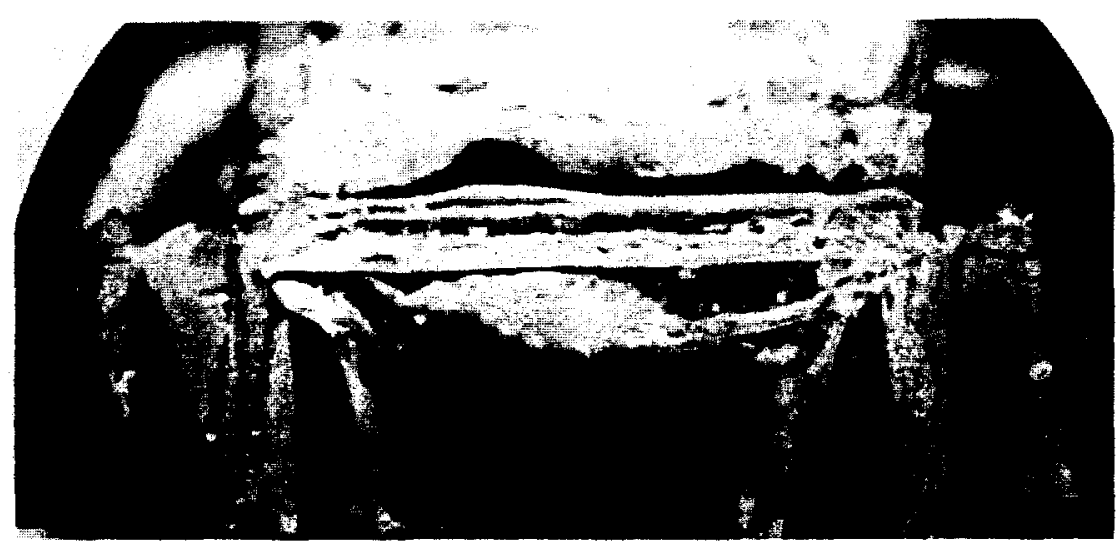

(b)

Fig. 10. Sections of (a) polyester and (b) vinyl ester bevel triggered tubes.

absorber. In general, a sudden drop in load occurs with the formation of a fracture line on one or more tube walls. When the distance between fracture lines is large the corresponding load reduction also tends to be large. When the fracture line distances vary, the load reductions also tend to vary. This observation corresponds with the standard deviations listed in Table 2 for fracture line distance. Tulip triggered specimens, which produce more uniform load-displacement curves, also have a smaller standard deviation for fracture line distances.

When the depth of delamination between the uniaxial fibers and the glass mats is large, the depth of cracks along the tube corners is also large. This reduces the stability of the crush zone because long segments of the 


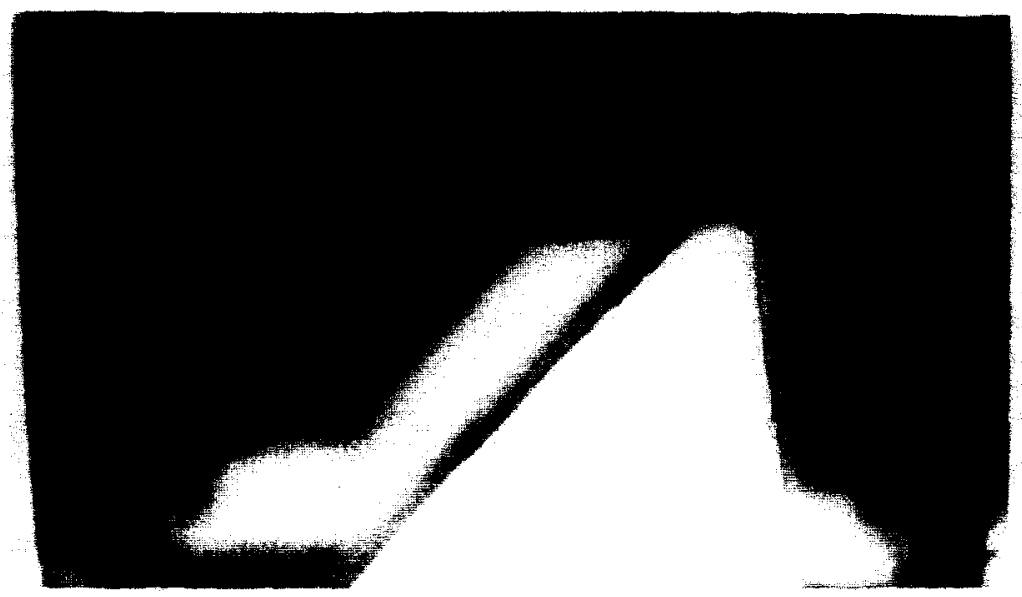

(a)

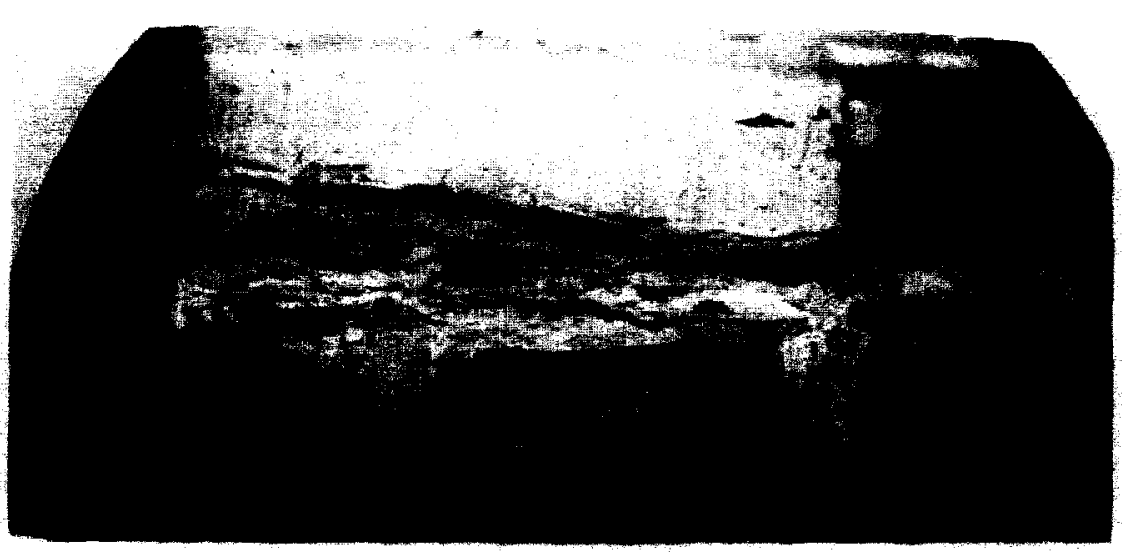

(b)

Fig. 11. Sections of (a) polyester and (b) vinyl ester tulip triggered tubes.

separated wall act more as independent members. The separation of the walls at the tube corners macroscopically resembles ripping.

In Figs 10 and 11 cross-sections of crushed tubes are shown. The macroscopic differences revealed between specimens sectioned in this way are small, but the bevel triggered specimens are seen generally to exhibit a greater amount of fracture within the central region. In addition, the pattern of fiber separation appears to be more aligned in planes for bevel triggered specimens, as shown schematically in Fig. 12. The differences reported above come from the examination of a number of sections of tubes with both vinyl ester and polyester resin types. A greater number of cracks can be observed for bevel triggered specimens than for tulip triggered specimens. 


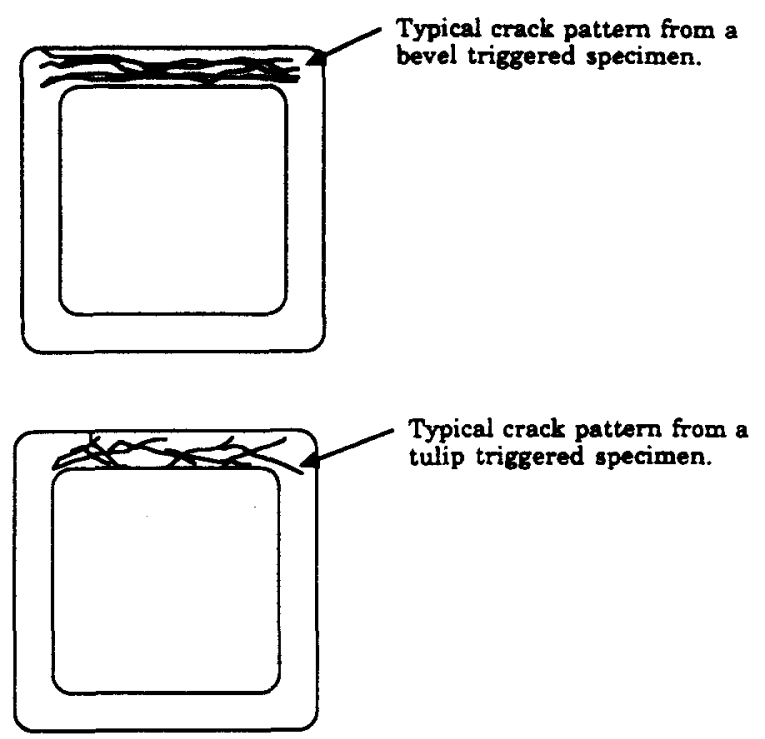

Fig. 12. Schematic illustration of typical crack patterns for the bevel and tulip triggers.

\section{DISCUSSION}

The primary difference in appearance between specimens crushed using the two triggers is the distance between fracture lines, which are formed periodically after delamination cracks have penetrated between the surface glass mats and the uniaxial fiber bundles. The shorter distance between fracture lines for tulip triggered than for bevel triggered tubes results in tulip triggered specimens having a greater degree of fracture both within the glass mats and the unidirectional fibers in addition to an increased regularity of fracture.

The difference in fracture line separation seems to be the result of the type of crack pattern that is produced from the trigger. The pattern that results from triggering appears to persist for the entire crushing process. In addition to affecting the crush load and energy absorption, the fracture behavior appears to affect the loading stability.

It is likely that the different fracture patterns change the way in which the load is supported during crushing. It can be imagined that at any instant the crush load must be supported by some structural element of the tube. Furthermore, there will be likely to be more than one structural element responsible for load support at any given moment and one of these elements will be most responsible for supporting the load. When the structural element that is primarily responsible for load support at that moment fails, another structural element must then take over, otherwise the gross 
Fig. 13. Schematic illustration of tube separation into different beams.

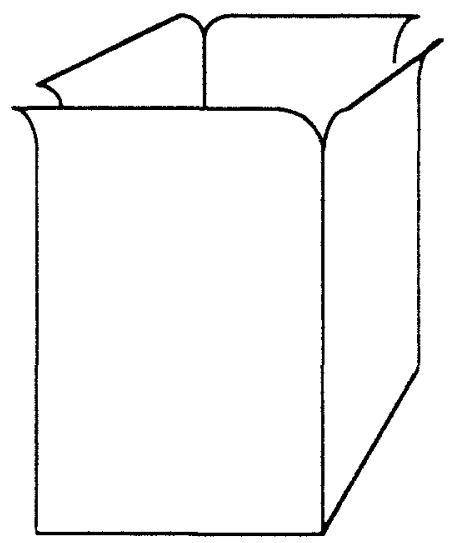

structure (the whole tube) will fail in a catastrophic and non-energyabsorbing way. Therefore, during crushing, primary load support is being passed from one structural element to another. This behavior is reflected in the load-displacement curves, where the load fluctuates as a result of loading and sudden unloading from the failure of different structural elements supporting the load at various times during crushing.

For this study, two sets of load-supporting structural elements can be identified. One set is the group of individual unidirectional fiber bundles that are separated as a result of cracks that form during crushing. The fiber bundles in bevel triggered tubes were found to be smaller and more aligned in parallel rows than for tulip triggered specimens. This reduced the ability of the bevel triggered tubes to support a load by both increasing the wall compliance and allowing the aligned fiber bundles to slide past each other more easily. The other types of support identified are the side-wall surface mats, which are held in place by hoop fibers circling the tube. The support of the surface mats therefore depends on the corner integrity. The depth to which the cracks penetrate at the corners seems to be related to both the layup and the type of triggering used. The layup, and in particular hoop reinforcement, apparently significantly affects the crack penetration depth. As the reinforcement was identifical for all tubes tested, the crack pattern produced by the trigger seems to have been responsible for differences in the corner crack penetration depth in this study. Therefore, the deeper crack penetration depth that resulted from the bevel trigger reduced the loadsupporting ability of the tubes.

The phenomenon of higher mean crush loads from specimens where cracks penetrate less deeply can be examined analytically. Each of the four walls of a square can be imagined to be a beam. When the cracks at the tube corners propagate to a certain depth, the wall segments separate and act as four individual beams, as shown in Fig. 13. These four beams will each be 


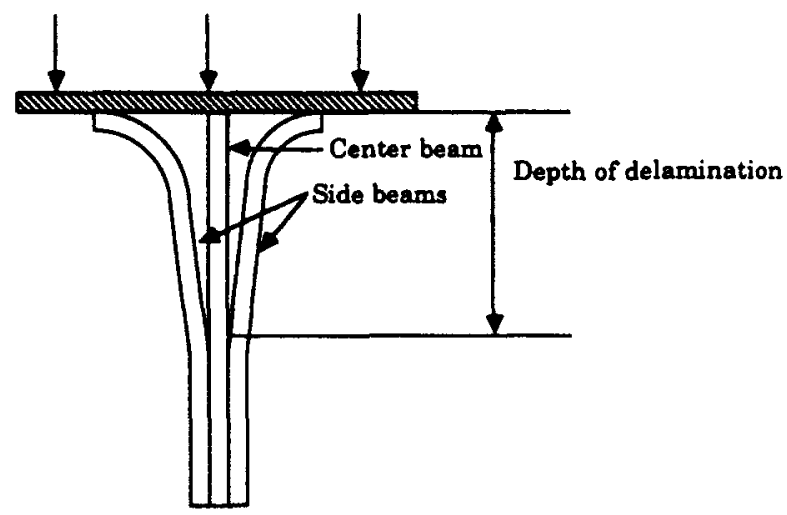

Fig. 14. Separation of each wall into three beam elements.

structurally similar. As delamination occurs approximately along the interface between the uniaxial fibers and the glass mat, each of the four beams can be further divided into three smaller beams, as shown in Fig. 14. The summation of the load supported by each of the 12 minibeams at the time of fracture gives the crush load level at that instant. However, in reality, each of the 12 minibeams can be further sub-divided into even smaller beams, which is part of the reason for the difference in energy absorption between tubes with the contrasting triggers.

For an illustrative model that explains the effect of crack penetration on crushing load, let us assume that the two outer minibeams of each wall, composed of the glass mats, fail in bending and that the center beam fails by buckling. A fracture line is created when the critical stress (and corresponding crush load) required for bending failure is reached for the two side beams.

The stress at which bending failure occurs can be determined from

$$
\sigma=\frac{M c}{I}
$$

if the applied bending moment at failure is known. Here, $\sigma$ is the bending tensile stress, $M$ is the applied bending moment, $c$ is the distance from the neutral axis, and $I$ is the cross-sectional moment of inertia.

The applied moment for the outer minibeams is the sum of moments from the axial downward loading and from the lateral frictional force, as shown in Fig. 15.

$$
M=P_{\mathrm{b}} f_{1}(L)-\mu P_{\mathrm{b}} f_{2}(L)
$$

where $f_{1}$ and $f_{2}$ are functions of length which can be written approximately as

$$
M=P_{\mathrm{b}} c_{1} L^{\alpha_{1}}-\mu P_{\mathrm{b}} c_{2} L^{\alpha_{2}}
$$




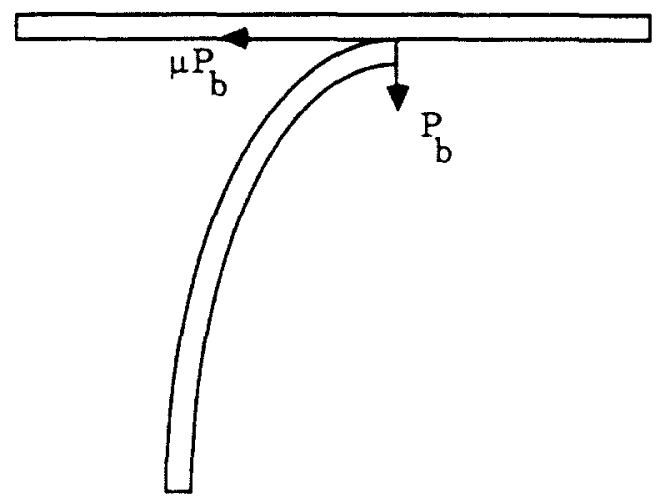

Fig. 15. Forces acting on bending element.

Here $L$ is the delamination distance, $P_{\mathrm{b}}$ is the load at bending failure, $\mu$ is the coefficient of friction between the crushing plate and the bending member, and the $c s$ and $\alpha$ s are constants, with

$$
\alpha_{1} \widetilde{>} \quad \alpha_{2} \approx 1
$$

Equation (1) can be rewritten as

$$
\sigma=\frac{M(h / 2)}{\frac{1}{12} b h^{3}}=\frac{6 M}{b h^{2}}
$$

The terms $b$ and $h$ represent the width and thickness respectively, of the beam cross-section that is subject to the bending load. By substituting the moment calculated in eqn (3) into eqn (4), the ultimate stress at the time of bending failure can be determined by

$$
\sigma_{\mathrm{u}}=\frac{6 P_{\mathrm{b}}\left(c_{1} L^{x_{1}}-\mu c_{2} L^{x_{2}}\right)}{b h^{2}}
$$

The load supported by the center beam at the time of fracture line formation can be calculated from the Euler buckling equation,

$$
P_{\mathrm{c}}=\frac{\pi^{2} E I}{L^{2}}=\frac{\pi^{2} E b_{\mathrm{c}} h_{\mathrm{c}}^{3}}{12 L^{2}}
$$

where $P_{\mathrm{c}}$ is the critical buckling load, $L$ is again the beam length produced by delamination, and $E$ is Young's modulus of the beam.

A summation can be taken by combining the load supported by the 12 independent minibeams to yield the total load at the time of fracture, $P_{\mathrm{t}}$ :

$$
P_{\mathrm{t}}=8 P_{\mathrm{b}}+4 P_{\mathrm{c}}
$$

By substituting eqns (5) and (6) into eqn (7), the relationship between the 
crack penetration depth and the load supportable at the time of fracture becomes

$$
P_{\mathrm{t}}=\frac{4 \sigma_{\mathrm{u}} b h^{2}}{3\left(c_{1} L^{x_{1}}-\mu c_{2} L^{x_{2}}\right)}+\frac{\pi^{2} E b_{\mathrm{c}} h_{\mathrm{c}}^{3}}{3 L^{2}}
$$

For both terms in eqn (8), an increase in $L$ results in a significant reduction in the load that may be supported at the time of fracture. It can be concluded that the crack penetration depth has a large effect on the crush load obtained during crushing. Also, it can be seen that an increase in friction also increases the total load at the time of fracture.

As stated previously, each of the 12 minibeams is actually separated into even smaller load-supporting members. The geometry of these smaller load members is probably the factor that determines the depth of corner crack penetration and delamination. The smaller members within the minibeams will probably be subject to either bending or buckling failure. It was assumed in the illustrative model that the load-supporting members in each of the tube walls had identical geometries. However, this is not true of the smaller members within the 12 minibeams. There is more separation within the walls of bevel triggered specimens and the cross-sectional shape of the individual members is approximately lamellar. The walls of tulip triggered specimens are relatively less fractured and the cross-section of these members is more nearly square. Therefore, the second term of eqn (8) would then become

$$
P_{\mathrm{c}}=\sum_{i} \frac{\pi^{2} E b_{\mathrm{c} i} h_{\mathrm{c} i}^{3}}{12 L^{2}}
$$

where $b_{\mathrm{c} i}$ and $h_{\mathrm{c} i}$ reflect the geometry of the load-carrying members produced by the additional splitting observed in the center part of the wall.

The dominating term in both the bending equation (eqn (1)) and the buckling equation (eqn (9)) is the cross-sectional moment of inertia, $I$. This term is strictly geometrical and is greater for a square cross-section than for a rectangular cross-section. In addition, if a summation is taken of area moments, it can be seen that the summation is greatest for the cross-section that has been separated into the smallest total number of members. Therefore, the structural stiffness, $E I$, is larger for tulip triggered specimens and is therefore a likely reason for the smaller depth of crack penetration at the tube corners.

\section{CONCLUSION}

Energy-absorbing ability and crushing behavior differ significantly for identical tubes that are triggered with a tulip as compared with the 
conventional bevel trigger. It appears that the deeper crack penetration and larger distance between fracture lines observed for bevel triggered specimens than for tulip triggered specimens are a result of the total number, pattern, and depth of cracks developed during crush initiation. These crack patterns appear to continue for the entire tube length, resulting in a crushing behavior that is the same for the entire length. The crack pattern affects energy absorption and loading constancy by establishing the size and shape of load-supporting minibeams. The size affects the ability of the individual elements to support load. Both size and shape seem to affect the friction between the crushing plate and the fiber bundles. Larger material segments increase load-supporting ability by producing a larger frictional reaction force by contact of the bending beams with the crushing plate. Triggering efficiency is apparently not improved by increasing the amount of fracture in the tube beyond the degree that is required for stable crush.

\section{ACKNOWLEDGEMENT}

Michael Czaplicki and Richard Robertson wish to acknowledge financial support from the Ford Motor Company during the course of this work.

\section{REFERENCES}

1. Thornton, P. H., Energy absorption in composite structures. J. Composite Mater., 13 (1979) 247-62.

2. Bannerman, D. C. \& Kindervator, C. M., Crash impact behavior of simulated composite fuselage elements. 9th European Rotorcraft Forum, September 1987.

3. Thornton, P. H., Harwood, J. J. \& Beardmore, P., Fiber reinforced plastic composites for energy absorption purposes. Composites Sci. Technol., 24 (1985) $275-98$.

4. Thornton, P. H. \& Edwards, P. J., Energy absorption in composite tubes. $J$. Composite Mater., 16 (1982) 521-45.

5. Berry, J. P. \& Hull, D., Effect of speed on the crushing of epoxy-glasscloth tubes. In Proc. 3rd Conf. Mechanical Properties at High Rates of Strain, ed. J. Harding. Inst. Phys. Conf. Ser. No. 70, 1985, pp. 463-70.

6. Czaplicki, M. J., Robertson, R. E. \& Thornton, P. H., Triggering of polymer composite tubes. In ASM-ESD Advanced Composites, ed. J. E. Hill, ASM International, Metals Park, Ohio, 1988, pp. 39-46.

7. Farley, G. L., Energy absorption of composite materials. J. Composite Mater., 17 (1983) 267-79.

8. Price, J. N. \& Hull, D., The crush performance of composite structures. In Composite Structures 4 Vol. 2, ed. I. Marshall. Elsevier, London, 1987, pp. $2.32-44$.

9. Thornton, P. H., Effect of trigger geometry on energy absorption of composite tubes. In ICCM-V, ed. W. C. Harrington, J. Strife \& A. K. Dhingra. Metallurgical Society, Warrendale, PA, 1985, pp. 1183-99. 